\title{
Time-Tradeoff Sequences for Analyzing Discounting and Time Inconsistency ${ }^{*}$
}

\author{
Arthur E. Attema, Han Bleichrodt, Kirsten I.M. Rohde, \& Peter P. Wakker \\ Department of Economics, Erasmus University, Rotterdam, the Netherlands
}

April, 2008

\begin{abstract}
This paper introduces time-tradeoff (TTO) sequences as a new tool to analyze time inconsistency and intertemporal choice. TTO sequences simplify the measurement of discount functions, requiring no assumption about utility. They also simplify the qualitative testing of time inconsistencies, and allow for quantitative measurements thereof. TTO sequences can easily be administered using only pencil and paper. They readily show which subjects are most prone to time inconsistencies. We further use them to axiomatically analyze and empirically test (quasi-)hyperbolic discount functions. An experiment demonstrates the feasibility of measuring TTO sequences. Our data falsify (quasi-)hyperbolic discount functions and call for the development of models that can accommodate increasing impatience.
\end{abstract}

KEYWORDS: Time inconsistency, time preference, stationarity, increasing impatience, hyperbolic discounting

JEL-CLASSIFICATION: D91; C91; E42

\footnotetext{
${ }^{*}$ Arthur Attema's and Han Bleichrodt's research was made possible through a VIDI-grant from the Netherlands Organization for Scientific Research (NWO).
} 


\section{Introduction}

Time inconsistency occurs if agents deviate from the plans they preferred a priori when offered the possibility to revise at the moment of actual choice. Strotz (1956) was the first to analyze the implications of time inconsistency in an economic model. It has since been well understood that time inconsistency lies at the heart of many economic phenomena. Time inconsistencies may arise due to changing preferences of agents (Phelps and Pollak 1968; Strotz 1956). Such changes in preferences can be modelled as strategic interactions between different selves within one agent (Asheim 1997; Peleg and Yaari 1973). They underly anomalies such as procrastination, temptation, and addiction. There is a close connection between time (in)consistency and (violations of) Samuelson's (1937) constant discount model. Because of the many empirical violations of constant discounting (Frederick, Loewenstein, and O'Donoghue 2002), Phelps and Pollak (1968) and others introduced alternative, hyperbolic, discount models.

Laibson $(1997,1998)$ demonstrated the importance of hyperbolic discounting for economics. He showed that hyperbolic discounting provides an explanation for many observed phenomena, such as the drop in consumption at retirement, the holding of illiquid assets, the extensive credit card borrowing, and undersaving. Present-biased hyperbolic discounters will want to pre-commit their future selves if they know that their future preferences will also be present-biased. Illiquid assets can serve as a precommitment device. Thus, hyperbolic discounters will have a higher tendency to invest in illiquid assets than constant discounters will. Agents with present-biased preferences will also want their future selves to save more than their future selves will actually want, which results in less savings than the agent would have liked after all. Time inconsistencies arising from present-biased preferences are central in many papers (Akerlof 1991, 2002; Angeletos et al. 2001; Asheim 1997; Barro 1999; DellaVigna and Malmendier 2004;Gul and Pesendorfer 2005; Harris and Laibson 2001; Krusell and Smith 2003; Luttmer and Mariotti 2003; O'Donoghue and Rabin 1999a, 1999b; Thaler and Benartzi 2004). Time inconsistencies may also arise in strategic situations when agents make incredible threats and do not follow a subgame perfect equilibrium. This is central in the determination of monetary policies, for 
instance (Kydland and Prescott 1977). In this paper we focus on time inconsistencies arising from changing preferences.

We start by introducing a general tool to facilitate the study of intertemporal choice. Our tool is especially suited to quantitatively measure the extent to which an agent is vulnerable to time inconsistency. One difficulty with the general analysis of intertemporal choice is that two different factors, time discounting and outcome utility, play a role, and it may not be so easy to disentangle them. To avoid this difficulty, most analyses of intertemporal discounting simply assume linear utility. Diminishing marginal utility will distort the findings of such analyses. It may, for instance, explain the so-called magnitude effect (Loewenstein and Prelec 1992).

A second difficulty with the analysis of intertemporal choice is that there are many empirical violations of the commonly used discounted utility model, and these further distort the conclusions drawn on the basis of this model. The most questionable assumption of discounted utility, extensively violated empirically, is intertemporal separability (Broome 1993, pp. 151-152; Gilboa 1989 p. 1155; Loewenstein and Elster 1992; Prelec and Loewenstein 1991). Many phenomena are based on violations thereof, such as habit formation (Becker 1996; Constantinides 1990; Wathieu 1997), sequence effects (Krabbe and Bonsel 1998; Guyse, Keller, and Eppel 2002; Loewenstein and Sicherman 1991) and, in the health domain, the dependence of quality of life on past and future health (Dolan 2000 p. 1743; Gold et al. 1996, p. 100; Loomes and McKenzie 1989 p. 303).

We introduce time-tradeoff (TTO) sequences to resolve the aforementioned difficulties. First, TTO sequences concern the receipt of single outcomes where intertemporal separability and its violations play no role and, second, TTO sequences are not affected by interactions with utility. Thus, as we will show, we can measure the discount function up to its power without any interaction with utility. To measure the power and, thus, the complete discount function, we either need one extra data point regarding utility and no time separability, or one extra data point regarding time separability and no utility. The latter approach is the first one available in the literature that measures the discount function in an entirely utility-free manner.

We next turn to applications of TTO sequences that can be based entirely on TTO sequences, and that need no extra data points. In particular, no extra assumption about utility is needed. The first application concerns time inconsistency. Hyperbolic discount functions accommodate time inconsistency, which implies arbitrage 
opportunities. The degree to which time inconsistency can arise and is empirically or normatively appropriate, is of central interest in the literature today. An important advance was presented by Prelec (2004), who introduced a theoretical measure of time inconsistency. One agent is more prone to time inconsistency and arbitrage than another if and only if the Pratt-Arrow measure of the logarithm of the discount function of the former always exceeds that of the latter. This result is the analog for intertemporal choice of the famous risk aversion measure of Pratt and Arrow for decision under risk.

Unfortunately, Prelec's measure seems complex to observe or analyze. In decision under risk, where the Pratt-Arrow utility measure was introduced, utility is the only subjective factor and it can readily be measured and analyzed. Risk premia provide a simple empirical criterion to test the Pratt-Arrow measure. In intertemporal choice, however, the discount function interacts with utility in seemingly inextricable manners. There is no analog to risk premia. Further, if we do succeed in measuring the discount function, then logarithms and derivatives remain to be taken to determine Prelec's measure. It is difficult to obtain reliable estimations of derivatives from data.

Surprisingly, using TTO sequences we can immediately estimate Prelec's index of time inconsistency. We can depict its graph using only pencil and paper, and we need not carry out the measurements and calculations just suggested. In particular, we need no measurement or assumption regarding utility. We can, thus, immediately identify which agents are most prone to time inconsistencies, as we show in a representation theorem and an experiment.

A second direct application of TTO sequences concerns empirical tests and axiomatizations of several hyperbolic discount models considered in the literature. Up until now, most studies only rejected constant discounting, but did not test for possible failures of the alternative models, or which of the several alternative models fitted better. Exceptions are Abdellaoui et al. (2008), who carried out an entire utility elicitation and essentially use intertemporal additive separability, and Keller and Strazzera (2002) and Pol and Cairns (2002) who assume linear utility. Using TTO sequences we can measure and critically test the alternatives more efficiently. We also indicate an application to Halevy's (2007) model with risky intertemporal choice.

The questions used to elicit TTO sequences are easy to comprehend for subjects, fostering reliable data. In an experiment, we demonstrate the feasibility by measuring TTO sequences of 55 subjects. Our experimental findings lead to a number of 
suggestions for new models of intertemporal choice, in particular regarding the development of discount functions that allow for increasing impatience. We also falsify some popular hyperbolic discount functions.

The outline of the paper is as follows. Section 2 describes discounted utility and introduces TTO curves. Section 3 introduces TTO sequences. The following sections present applications. Section 4 shows how TTO sequences plus some minimal extra information can be used to measure the discount function. Section 5 considers qualitative tests of impatience, and Section 6 quantitative measurements of the degree of inconsistency. Axiomatizations and tests of popular parametric families of discounting are in Section 7. The following sections present an experiment. Section 8 describes the method, Section 9 some results that can be inferred using only pencil and paper, and Section 10 detailed statistical tests. Section 11 discusses the experiment, Section 12 discusses some general points, and Section 13 concludes.

\section{Discounted Utility and Time-Tradeoff Curves}

We consider preferences between outcome streams. An outcome stream $\left(\mathrm{t}_{1}: \mathrm{x}_{1}, \ldots, \mathrm{t}_{\mathrm{m}}: \mathrm{x}_{\mathrm{m}}\right)$ yields outcome $\mathrm{x}_{\mathrm{i}}$ at time point $\mathrm{t}_{\mathrm{i}}$ for $\mathrm{i}=1, \ldots, \mathrm{m}$ and nothing at other time points. Most of the results in this paper hold for general outcomes, with the outcome set for instance a finite set of qualitative health states. For simplicity of presentation we assume, however, that outcomes are monetary and nonnegative, with the neutral outcome "nothing" equated with the 0 outcome. Time point $\mathrm{t}=0$ corresponds with the present. Throughout this paper, we assume discounted utility, which in this paper refers to general, possibly nonconstant, discounting. Outcome streams are evaluated through

$$
\operatorname{DU}\left(\mathrm{t}_{1}: \mathrm{x}_{1}, \ldots, \mathrm{t}_{\mathrm{m}}: \mathrm{x}_{\mathrm{m}}\right)=\sum_{\mathrm{i}=1}^{\mathrm{m}} \varphi\left(\mathrm{t}_{\mathrm{i}}\right) \mathrm{U}\left(\mathrm{x}_{\mathrm{i}}\right)
$$

with $\varphi$ the discount function and $\mathrm{U}$ the (instant) utility function. We assume: (a) $\varphi(t)$ $>0$ for all $\mathrm{t}$; (b) $\varphi$ is strictly decreasing (impatience) and continuous; (c) $\mathrm{U}(0)=0$; (d) $\mathrm{U}$ is strictly increasing and continuous. The functions $\varphi$ and $\mathrm{U}$ in Eq. 2.1 are ratio scales, i.e.

In Eq. $2.1, \varphi$ can be replaced by $\varphi / \lambda$ and $U$ by $U / \lambda^{\prime}$ for any $\lambda>0$ and $\lambda^{\prime}>0$, 
where no other replacement is possible. We used reciprocal constants for later convenience. In the literature, a normalization $\varphi(0)=1$ (taking $\lambda=\varphi(0)$ in Eq. 2.2) is often assumed, but it is more convenient for this paper not to commit to such a scaling.

The summation in Eq. 2.1 implies intertemporal separability, the most questionable assumption of discounted utility. To depend on this assumption as little as possible, most of this paper will focus on outcome streams ( $\mathrm{t}: \mathrm{x})$ with only one nonzero outcome, called timed outcomes. We will later show how from timed outcomes we can measure functions $\tau$ on the time axis such that:

There exist $\mathrm{r}>0$ and $\ell=\ln (\lambda) \in \mathbb{R}$ such that $\ln (\varphi(\cdot))=\ell+\mathrm{r} \tau(\cdot)$.

Formally, we call a function $\tau$ a TTO curve if it satisfies Eq. 2.3. Eq. 2.2 shows that $\ell$ or, equivalently, $\lambda$, are immaterial. They can be chosen arbitrarily and do not affect preference. They are empirically meaningless in the sense of Stevens (1946; see also Narens 2002). The parameter $r$, however, is empirically meaningful. It can be seen that, the larger is $r$, given $\tau$, the more convex are the terms in Eq. 2.1 with more impatience and more tolerance for inequality of outcomes over time. Hence, to completely measure intertemporal attitudes we have to find out what $r$ is.

The following observation shows that preferences over timed outcomes will never enable us to determine $\mathrm{r}$ :

If $\varphi(t) \mathrm{U}(\mathrm{x})$ represents preferences over timed outcomes ( $\mathrm{t}: \mathrm{x})$, then so does

$$
(\varphi / \lambda)^{\mathrm{r}}\left(\mathrm{U} / \lambda^{\prime}\right)^{\mathrm{r}} \text { for any } \lambda>0, \lambda^{\prime}>0 \text {, and } \mathrm{r}>0 \text {. }
$$

To entirely determine the discount function, we have to combine TTO curves with some information beyond timed outcomes.

\section{Time-Tradeoff Sequences}

A time-tradeoff $(T T O)$ sequence is a sequence $\mathrm{t}_{0}, \ldots, \mathrm{t}_{\mathrm{n}}$ of time points such that there exist two outcomes $\beta<\gamma$ with 


$$
\begin{aligned}
\left(\mathrm{t}_{0}: \beta\right) & \sim\left(\mathrm{t}_{1}: \gamma\right) \\
\left(\mathrm{t}_{1}: \beta\right) & \sim\left(\mathrm{t}_{2}: \gamma\right) \\
& \cdot \\
& \cdot \\
\left(\mathrm{t}_{\mathrm{n}-1}: \beta\right) & \sim\left(\mathrm{t}_{\mathrm{n}}: \gamma\right)
\end{aligned}
$$

That is, each delay between two consecutive time points exactly offsets the same outcome improvement. This delay, $\mathrm{d}_{\mathrm{i}}=\mathrm{t}_{\mathrm{i}}-\mathrm{t}_{\mathrm{i}-1}$, is called the willingness to wait $(W T W)$ Stationarity means that the WTW is constant, so that the points $\mathrm{t}_{0}, \ldots, \mathrm{t}_{\mathrm{n}}$ are equally spaced in time units. We consider a convenient TTO curve, being $\ln (\varphi)$ normalized at $t_{0}$ and $t_{n}$ :

$$
\tau_{\mathrm{t}_{0}, \mathrm{t}_{\mathrm{n}}}(\mathrm{t})=\frac{\ln (\varphi(\mathrm{t}))-\ln \left(\varphi\left(\mathrm{t}_{\mathrm{n}}\right)\right)}{\ln \left(\varphi\left(\mathrm{t}_{0}\right)\right)-\ln \left(\varphi\left(\mathrm{t}_{\mathrm{n}}\right)\right)}
$$

The following result shows that, whereas TTO sequences are not equally spaced in time units if stationarity is violated, they are always equally spaced in TTO-curve units. Because its proof is instructive, we give it in the main text.

OBSERVATION 3.1. Any TTO sequence $t_{0}, \ldots, t_{n}$ is equally spaced in $\ln (\varphi)$ units, and in the units of any TTO-curve. In particular,

$$
\tau_{\mathrm{t}_{0}, \mathrm{t}_{\mathrm{n}}}\left(\mathrm{t}_{\mathrm{j}}\right)=1-\frac{\mathrm{j}}{\mathrm{n}} \text { for all } \mathrm{j}
$$

PROOF. $\frac{\varphi\left(\mathrm{t}_{0}\right)}{\varphi\left(\mathrm{t}_{1}\right)}=\frac{\varphi\left(\mathrm{t}_{1}\right)}{\varphi\left(\mathrm{t}_{2}\right)}=\cdots=\frac{\varphi\left(\mathrm{t}_{\mathrm{n}-1}\right)}{\varphi\left(\mathrm{t}_{\mathrm{n}}\right)}=\frac{\mathrm{U}(\gamma)}{\mathrm{U}(\beta)}$. In other words,

$$
\ln \left(\varphi\left(\mathrm{t}_{0}\right)\right)-\ln \left(\varphi\left(\mathrm{t}_{1}\right)\right)=\ln \left(\varphi\left(\mathrm{t}_{1}\right)\right)-\ln \left(\varphi\left(\mathrm{t}_{2}\right)\right)=\cdots=\ln \left(\varphi\left(\mathrm{t}_{\mathrm{n}-1}\right)\right)-\ln \left(\varphi\left(\mathrm{t}_{\mathrm{n}}\right)\right)
$$

all differences being equal to $\ln (\mathrm{U}(\gamma))-\ln (\mathrm{U}(\beta))$. Thus, $\mathrm{t}_{0}, \ldots, \mathrm{t}_{\mathrm{n}}$ are equally spaced in $\ln (\varphi)$ units. They are also equally spaced in the units of any TTO sequence, such as $\tau_{t_{0}, t_{n}}$. Because $\tau_{t_{0}, t_{n}}$ is 1 at $t_{0}$ and 0 at $t_{n}$, with $n$ equally big steps $\tau_{t_{0}, t_{n}}\left(t_{j-1}\right)-\tau_{t_{0}, t_{n}}\left(t_{j}\right)$ of size $1 / \mathrm{n}$ in between, the observation follows.

Figure 3.1 depicts some observed values of $\tau_{\mathrm{t}_{0}, \mathrm{t}_{\mathrm{n}}}$. The values come from the experiment reported later, reflecting subject 38's indifferences 
(05 months: €700) (12 months: €900)

(12 months: €700) (18 months: €900)

(18 months: €700) (25 months: €900)

(25 months: €700) (37 months: €900)

(37 months: €700) (49 months: €900)

so that $\mathrm{n}=5, \mathrm{t}_{0}=5, \mathrm{t}_{1}=12, \mathrm{t}_{2}=18, \mathrm{t}_{3}=25, \mathrm{t}_{4}=37$, and $\mathrm{t}_{5}=49$.

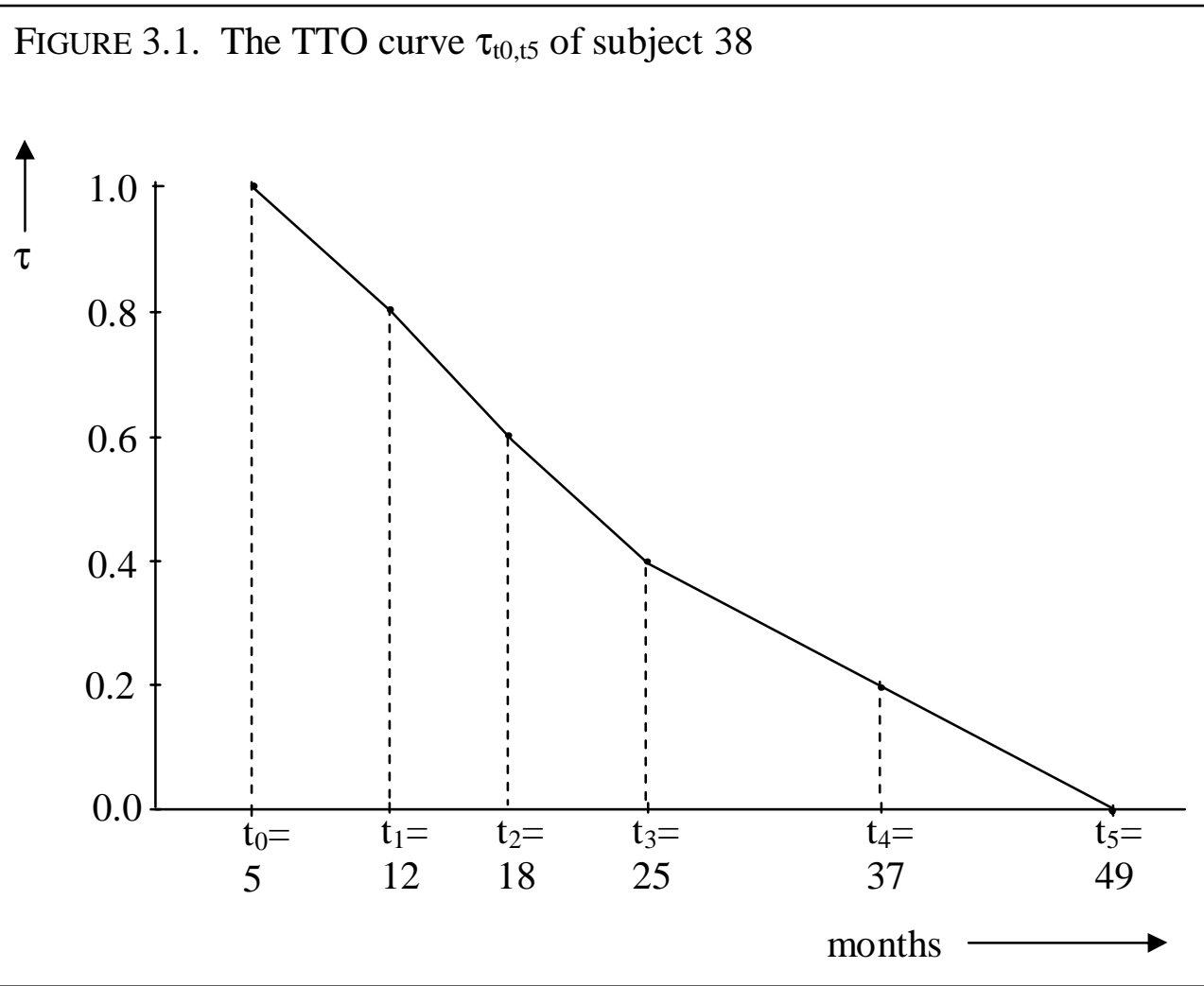

We can obtain more refined information about the TTO curve by taking $\gamma$ and $\beta$ closer to each other. We can cover a larger interval than $\left[\mathrm{t}_{0}, \mathrm{t}_{\mathrm{n}}\right]$ by setting $\mathrm{t}_{0}$ smaller (e.g. $\mathrm{t}_{0}=0$, as done in some questions in the experiment) and by using more steps so that we attain a larger value $t_{n}$. Further, to fit the data points, we can choose curves other than through linear interpolation as we use here for simplicity. Thus, using TTO sequences, we can measure TTO curves, and $\ln (\varphi)$ up to its unit r, to any desired degree of precision. 


\section{Using TTO Sequences to Measure the Discount Function}

To completely measure the discount function $\varphi$ we have to use TTO curves alongside further data. We present two ways to accomplish such a measurement. First, assume that we have measured a TTO curve $\tau$ together with an estimate of a utility ratio $\mathrm{U}(\gamma) / \mathrm{U}(\beta)$, for some $\gamma>\beta>0 .{ }^{1}$ Then we find time points $\mathrm{t}$ and $\mathrm{s}$ to generate an indifference $(\mathrm{t}: \beta) \sim(\mathrm{s}: \gamma)$. Substituting Eq. 2.1, setting $\lambda=1$ in Eq. 2.4, and taking logarithms implies

$$
\varphi(\cdot)=\mathrm{e}^{\mathrm{r} \tau(\cdot)} \text { with } \mathrm{r}=\frac{\ln (\mathrm{U}(\gamma) / \mathrm{U}(\beta))}{\tau(\mathrm{t})-\tau(\mathrm{s})} .
$$

Thus we have identified $\mathrm{r}$ and, consequently, the complete discount function $\varphi$.

Figure 4.1 displays the discount function of subject 38 if we have the extra estimation

$$
\mathrm{U}(900) / \mathrm{U}(700)=1.12
$$

which is plausible under the diminishing marginal utility commonly assumed in empirical studies.

For a second, utility-free, method to estimate the discount function based on a TTO curve, assume that, besides $\tau$ (with $\varphi=\mathrm{e}^{\mathrm{r} \tau}$ ), we observe an indifference

$$
\left(t: x, t^{\prime}: x\right) \sim\left(s: x, s^{\prime}: x\right) \text { for } s>t>t^{\prime}>s^{\prime}
$$

(where s stands for spread out and $\mathrm{t}$ for tight). Note that only one nonzero outcome $\mathrm{x}$ is involved. Substituting DU (Eq. 2.1) and dropping the common factor U(x), we obtain

$$
e^{r \tau(t)}+e^{r \tau\left(t^{\prime}\right)}=e^{r \tau(s)}+e^{r \tau\left(s^{\prime}\right)}
$$

There exists a unique $r$ that solves this equality for every quadruple $\mathrm{e}^{\tau(\mathrm{t})}, \mathrm{e}^{\tau\left(\mathrm{t}^{\mathrm{t}}\right)}, \mathrm{e}^{\tau(\mathrm{s})}$, and $\mathrm{e}^{\tau\left(\mathrm{s}^{\prime}\right)} .^{2}$ Under discounted utility, $\mathrm{r}$ must be positive which can be seen to be equivalent

\footnotetext{
${ }^{1}$ Given that we can always normalize $\mathrm{U}(0)=0$ and $\mathrm{U}(\beta)=1$, the assumption amounts to observing one utility value $\mathrm{U}(\gamma)$

${ }^{2}$ Equalities of this kind are often studied under expected utility with exponential utility $\mathrm{e}^{\mathrm{r} \tau}$. Eq. 4.3 results if a fiftyfifty gamble with outcomes $\tau(\mathrm{t})$ and $\tau\left(\mathrm{t}^{\prime}\right)$ is equivalent to one with outcomes $\tau(\mathrm{s})$ and $\tau\left(\mathrm{s}^{\prime}\right)$. Including negative
} 
to $\tau(\mathrm{t})+\tau\left(\mathrm{t}^{\prime}\right)>\tau(\mathrm{s})+\tau\left(\mathrm{s}^{\prime}\right)$ (corresponding with convexity of $\mathrm{e}^{\mathrm{r} \tau}$ in $\left.\tau\right)$. If this inequality is violated, then DU is violated. In particular, violations of time separability will generate such violations.

FIGURE 4.1. The discount function using Figure 3.1 and Eq. 4.1

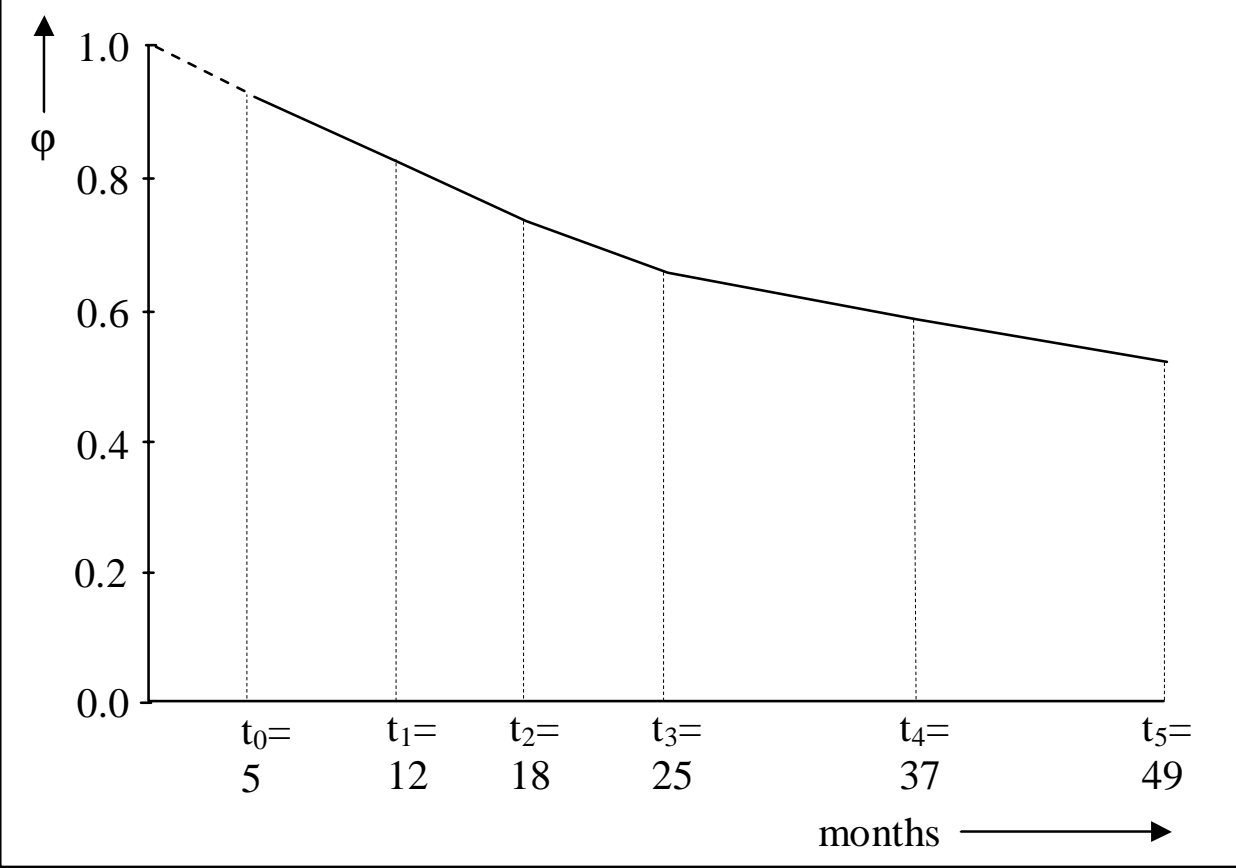

Figure 4.2 depicts a discount function that we obtained for subject 38 . We used the extra indifference

$$
(12: 700,16: 700) \sim(6: 700,24: 700),
$$

observed from this subject in a pilot experiment, as a version of Eq. 4.2 to estimate $r$. We obtained an estimated power $\mathrm{r}=0.58$.

powers $\mathrm{r}$ for risk aversion and power $\mathrm{r}=0$ for risk neutrality, the exponential family covers any degree of risk aversion and can accommodate any quadruple $\tau(\mathrm{s})<\tau(\mathrm{t})<\tau\left(\mathrm{t}^{\prime}\right)<\tau\left(\mathrm{s}^{\prime}\right)$ in Eq. 4.3. 


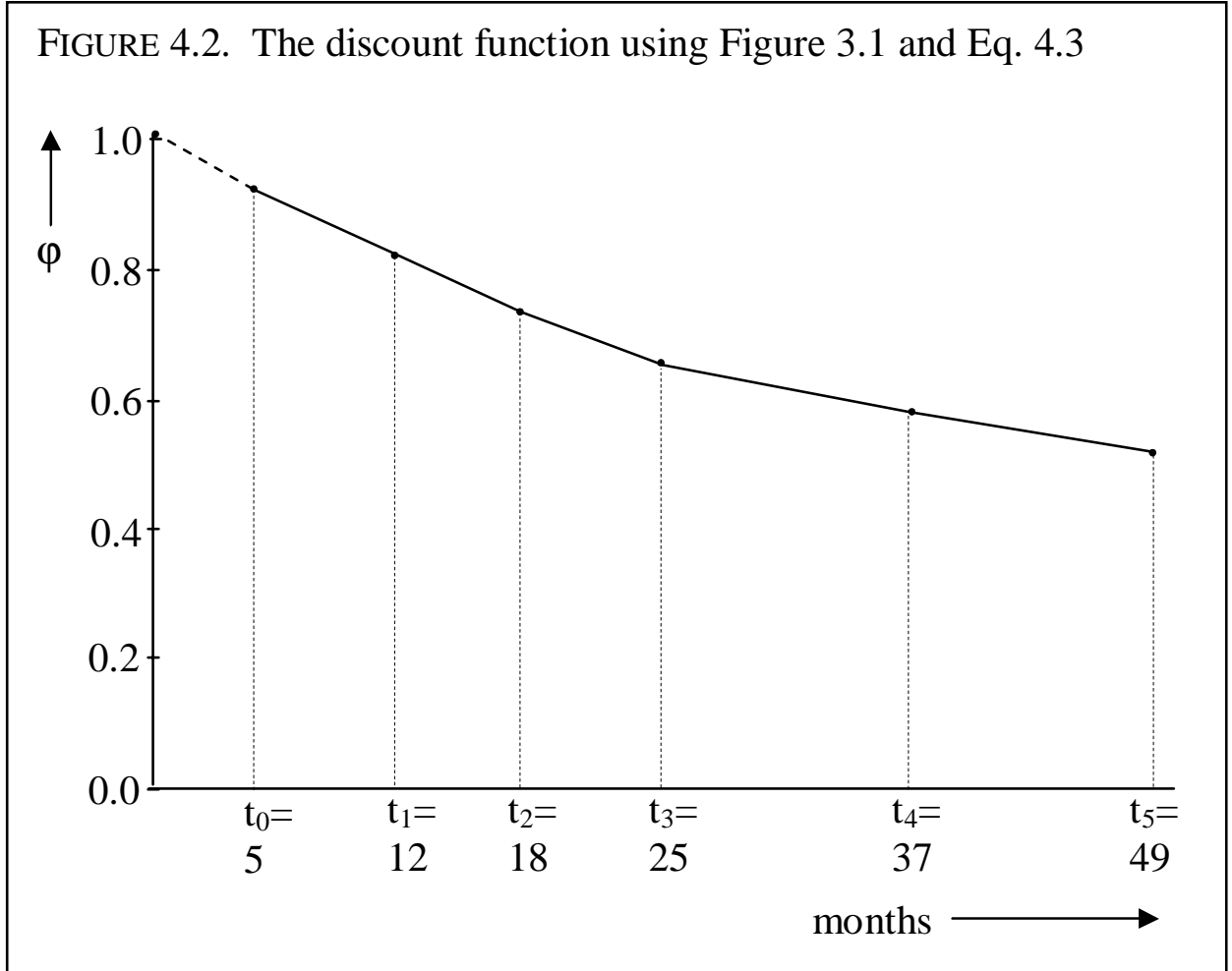

The two examples (one with Eq. 4.1 and one with Eq. 4.4), showed how TTO curves, together with minimal extra data, provide measurements and tests of discount functions in deterministic models. Given that the major empirical problems for DU occur for outcome streams with more than one outcome, and the ease of measuring TTO curves, we think that the analysis of intertemporal choice can be improved by giving a central role to TTO curves. If only one extra data point of utility is used, then we can make a special effort to obtain this data point as reliably as possible. This task will be easier and can be done more reliably than having to estimate the complete utility function (Abdellaoui et al. 2008; Chapman 1996; Andersen, Harrison, Lau, and Rutström 2008) or, worse, simply assuming that utility is linear as done mostly in the literature. If only one indifference based on time separability is used, then we can similarly make a special effort to obtain this indifference as reliably as possible. The latter approach identifies time discounting in an entirely utility-free way. It is, obviously, not affected by errors in utility measurement.

Empirical tests of the procedures described here, with proper error theories for choice incorporated, are left to future studies. In this paper we focus on TTO sequences because they can measure time inconsistencies, a topic that has received 
much attention in the recent literature. We present this application, together with some other applications, in the following sections.

\section{TTO Sequences and Qualitative Tests of Time Inconsistency}

This section shows how TTO sequences can be used to qualitatively examine deviations from stationarity. Throughout this section, we use no other information than provided by the TTO curve. Constant discounting holds if $\varphi(t)=\delta^{\mathrm{t}}$ for a discount factor $\delta$ with $0<\delta<1$. Then delaying all outcomes in some outcome streams by a period $\varepsilon$ implies that all discounted utilities are multiplied by the same factor $\delta^{\varepsilon}$, so that the ordering of the time streams is not affected and constant impatience holds indeed. It is well-known that the reversed implication also holds under common assumptions, that is, constant impatience implies constant discounting (Koopmans 1960). Decreasing impatience holds if an indifference $(\mathrm{s}: \mathrm{x}) \sim(\mathrm{t}: \mathrm{y})$, with $\mathrm{s}$ $<\mathrm{t}$ and $\mathrm{x}<\mathrm{y}$ implies $(\mathrm{s}+\varepsilon: \mathrm{x}) \leqslant(\mathrm{t}+\varepsilon$ : $\mathrm{y})$ for all $\varepsilon>0$. Then a common delay brings more willingness to wait for a better outcome. Increasing impatience holds if the weak preference in the implication is reversed. A TTO sequence readily identifies constant, increasing, or decreasing impatience through constant, decreasing, or increasing WTW (i.e., $\mathrm{t}_{\mathrm{j}+1}-\mathrm{t}_{\mathrm{j}}$ ).

In general, violations of stationarity (constant impatience) need not imply time inconsistency (Dasgupta and Maskin, 2005, section I; Harvey, 1995 p. 389; Thaler, 1981). Under an assumption of homogeneous time, however, entailing that we can use stopwatch time (we can always reset the clock at 0 at the time point of choosing between outcome streams), the two conditions become equivalent. This will be assumed throughout this paper. It is implicitly assumed in many papers. Violations of stationarity then imply time inconsistency and vulnerability to arbitrage. We will return to this point in Section 6.

Whether a function is convex, linear, or concave is not affected by normalizations. Hence, $\tau$ is the same as $\ln (\varphi)$ in this regard. We summarize the observations made. 
OBSERVATION 5.1. Stationarity implies linearity of the TTO curve and of $\ln (\varphi)$. Decreasing impatience implies convexity of the TTO curve and of $\ln (\varphi)$. Increasing impatience implies concavity of the TTO curve and of $\ln (\varphi)$.

An interesting interpretation of TTO curves results if we assume that deviations from stationarity are due to a nonlinear perception of time. That is, a person perceives time as $f(t)$ instead of $t$, and discounts exponentially in the (mis)perceived $f$ units. It

leads to the discount function $\varphi(t)=\mathrm{e}^{\mathrm{rf}(\mathrm{t})}$. Because we have $\varphi(t)=\mathrm{e}^{\mathrm{r} \tau(\mathrm{t})}$, it follows that $\tau$ can be interpreted as a time (mis)perception function $\mathrm{f}$. In other words, TTO curves provide the time units in terms of which discounting is constant.

\section{TTO-Sequences and a Quantitative Measure of Time Inconsistency}

This section shows how TTO sequences can be used to obtain a quantitative measure of time inconsistency. This measure will show to what extent people are prone to arbitrage because of their time inconsistency. We again use no other information than provided by TTO curves. Consider the following two indifferences, similar to Eq. 3.1.

$$
\begin{aligned}
& (\mathrm{s}: \beta) \sim(\mathrm{t}: \gamma) \text { and }(\mathrm{s}+\sigma: \beta) \sim(\mathrm{t}+\sigma+\varepsilon: \gamma) \\
& \text { for } \mathrm{s}<\mathrm{t} \text { (s for "soon"), } \beta<\gamma, \text { and } \sigma>0 .
\end{aligned}
$$

For the special case of $\mathrm{s}+\sigma=\mathrm{t}$, the indifferences provide a TTO sequence $\mathrm{t}_{0}=\mathrm{s}, \mathrm{t}_{1}=\mathrm{t}$ $=\mathrm{s}+\sigma$, and $\mathrm{t}_{2}=\mathrm{t}+\sigma+\varepsilon$. We have $\varepsilon>0$ under decreasing impatience, $\varepsilon=0$ under constant impatience, and $\varepsilon<0$ under increasing impatience. Thus, $\varepsilon$ can be taken as an index of deviation from stationarity. For $\varepsilon>0$, we, indeed, obtain the following violations of stationarity:

$$
(\mathrm{s}: \beta) \geqslant\left(\mathrm{t}^{\prime}: \gamma\right) \text { and }(\mathrm{s}+\sigma: \beta) \preccurlyeq\left(\mathrm{t}^{\prime}+\sigma: \gamma\right) \text { with at least one preference strict }
$$

for all $t \leq t^{\prime} \leq t+\varepsilon$ and for no other $t^{\prime}$. The interval $[t, t+\varepsilon]$, thus, designates the domain of time inconsistency and arbitrage: At time 0 the person, when endowed with $(s+\sigma: \beta)$, is willing to exchange it for $\left(t^{\prime}+\sigma: \gamma\right)$. When asked to reconsider at time point 
$\sigma$, the person now perceives of the options as $(\mathrm{s}: \beta)$ and $\left(t^{\prime}: \gamma\right)$, and is willing to go back to the $\beta$-option. ${ }^{3}$ The person is willing to pay small amounts for the two exchanges (take it small enough not to affect preference otherwise). Then the person has ended up at the original endowment less some money, which entails arbitrage. Benabou and Tirole (2002), Gruber and Koszegi (2001), Laibson (1997), O'Donoghue and Rabin (1999a), Prelec (2004), Strotz (1956), Thaler and Benartzi (2004), and numerous others derived various similar choice anomalies from Eq. 6.2. For example, a sophisticated person who is informed about the arbitrage possibility beforehand may avoid it but then becomes vulnerable to commitments to dominated options, due to lack of future self-control. Cubitt and Sugden (2001) pointed out that an agent may refuse a trade that is not isolated but part of arbitrage.

For $\varepsilon<0$ in Eq. 6.1, as is typical of increasing impatience, we have

$$
(s: \beta) \preccurlyeq\left(t^{\prime}: \gamma\right) \text { and }(s+\sigma: \beta) \geqslant\left(t^{\prime}+\sigma: \gamma\right) \text { with at least one preference strict }
$$

for all $\mathrm{t}+\varepsilon \leq \mathrm{t}^{\prime} \leq \mathrm{t}$ and for no other $\mathrm{t}^{\prime}$. Now $[\mathrm{t}+\varepsilon, \mathrm{t}]$ is the domain of arbitrage.

Consider next another preference relation $\geqslant *$, satisfying the assumptions of the preceding sections as does $\geqslant$, with corresponding $\varphi^{*}, U^{*}, \tau^{*}$.

DEFINITION 6.1. $\geqslant *$ exhibits more decreasing impatience than $\geqslant$ if the equivalences for $\geqslant$ in Eq. 6.1 plus $\left(\mathrm{s}: \beta^{*}\right) \sim^{*}\left(\mathrm{t}: \gamma^{*}\right)$ imply $\left(\mathrm{s}+\sigma: \beta^{*}\right) \preccurlyeq^{*}\left(\mathrm{t}+\sigma+\varepsilon: \gamma^{*}\right)$.

Prelec (2004) gave an equivalent definition. Under decreasing impatience for $\geqslant$ and $\gtrless^{*}$, the condition of Definition 6.1 and Eq. 6.1 imply, for

$$
\left(\mathrm{s}: \beta^{*}\right) \sim^{*}\left(\mathrm{t}: \gamma^{*}\right) \text { and }\left(\mathrm{s}+\sigma: \beta^{*}\right) \sim^{*}\left(\mathrm{t}+\sigma+\varepsilon^{*}: \gamma^{*}\right) \text {, }
$$

that either $\varepsilon^{*}$ exceeds $\varepsilon>0$, or that such a $\varepsilon^{*}$ does not exist. In the first case the domain $\left[\mathrm{t}, \mathrm{t}+\varepsilon^{*}\right]$ of arbitrage for $\geqslant *$ exceeds the corresponding domain $[\mathrm{t}, \mathrm{t}+\varepsilon]$ for $\geqslant$. In the second case the domain for arbitrage for $\geqslant *$ is in fact $[t, t+\infty)$, as is readily verified, which obviously exceeds the corresponding domain $[t, t+\varepsilon]$ for $\succcurlyeq$.

There is also interest in increasing impatience, because of which we extend Definition 6.1.

\footnotetext{
${ }^{3}$ In the latter step we use homogeneity of time.
} 
DEFINITION 6.2. $\geqslant *$ exhibits more increasing impatience than $\geqslant$ if the equivalences in Eq. 6.1 plus $\left(\mathrm{s}: \beta^{*}\right) \sim^{*}\left(\mathrm{t}: \gamma^{*}\right)$ imply $\left(\mathrm{s}+\sigma: \beta^{*}\right) \geqslant *\left(\mathrm{t}+\sigma+\varepsilon: \gamma^{*}\right)$.

For preference relations with increasing impatience, the arbitrage domain $[\mathrm{t}+\varepsilon, \mathrm{t}]$ is larger as the increase in impatience is larger.

The following theorem shows that TTO curves identify proneness to arbitrage. As usual, $\tau^{*}$ is more convex than $\tau$ if there exists a convex transformation $\mathrm{f}$ such that $\tau^{*}(\mathrm{t})=\mathrm{f}(\tau(\mathrm{t}))$ for all $\mathrm{t}$, which holds if and only if $-\frac{\tau^{*^{\prime \prime}}}{\tau^{* \prime}} \geq-\frac{\tau^{\prime \prime}}{\tau^{\prime}}$ everywhere on their domain. Note that, whereas the Pratt-Arrow index is an index of concavity for increasing functions, the functions $\tau$ and $\tau^{*}$ are decreasing. Then the Pratt-Arrow index is an index of convexity rather than of concavity. Analogously, $\tau^{*}$ is more concave than $\tau$ if there exists a concave transformation $f$ such that $\tau^{*}(t)=f(\tau(t))$ for all $\mathrm{t}$, which holds if and only if $\frac{\tau^{*^{\prime \prime}}}{\tau^{*^{\prime}}} \geq \frac{\tau^{\prime \prime}}{\tau^{\prime}}$ everywhere on their domain.

The aforementioned comparative convexity and concavity definitions are not affected by a change in unit or level. Hence, $\tau$ has the same degree of convexity as $\ln (\varphi)$ :

$$
-\frac{\tau^{\prime \prime}}{\tau^{\prime}}=-\frac{\ln (\varphi)^{\prime \prime}}{\ln (\varphi)^{\prime}}
$$

The following theorem adapts Prelec's (2004) Proposition 1, stating conditions in terms of TTO curves rather than $\ln (\varphi)$. We also add results on increasing impatience.

THEOREM 6.3. Assume that $\geqslant$ and $\geqslant *$ satisfy discounted utility (Eq. 2.1), with a TTO curve $\tau$ for $\geqslant$ and a TTO curve $\tau^{*}$ for $\geqslant *$.

(i) $\quad \geqslant *$ exhibits more decreasing impatience than $\geqslant$ if and only if $\tau^{*}$ is more convex than $\tau$.

(ii) $\quad \geqslant *$ exhibits more increasing impatience than $\geqslant *$ if and only if $\tau^{*}$ is more concave than $\tau$. 
Theorem 6.3 demonstrates formally that the degree of convexity of a TTO-curve determines the degree of decreasing impatience and, thus, the domain for arbitrage and the proneness to anomalies, in the sense of Prelec (2004). From a mathematical perspective, the move of Theorem 6.3(i) from Prelec's Proposition 1 is elementary, replacing convexity of $\ln (\varphi)$ by the equivalent convexity of $\tau$. From an empirical perspective the move is crucial though, because $\tau$ is directly observable whereas $\ln (\varphi)$ is not.

\section{TTO-Sequences to Axiomatize and Test Parametric Families of Discount Functions}

Observation 5.1 demonstrated how TTO sequences can be used to test whether Samuelson's constant discounting model holds. In this section we investigate alternative discount functions. A popular function to capture decreasing impatience is the quasi-hyperbolic discount function (Phelps and Pollak, 1968; Laibson 1997). It is given by

$$
\begin{aligned}
& \varphi(\mathrm{t})=1 \text { if } \mathrm{t}=0 \text { and } \\
& \varphi(\mathrm{t})=\beta \delta^{\mathrm{t}} \text { if } \mathrm{t}>0,
\end{aligned}
$$

for a constant $\beta \leq 1$ with, again, $0<\delta<1$. Under quasi-hyperbolic discounting we have decreasing impatience only at time point 0 , and constant impatience thereafter. The following observation readily follows from substitution. Gul and Pesendorfer (2005, Theorem 4) provide an alternative characterization in terms of choices between decision problems.

OBSERVATION 7.1. Quasi-hyperbolic discounting holds if and only if WTW $\left(\mathrm{t}_{\mathrm{j}+1}-\mathrm{t}_{\mathrm{j}}\right)$ for TTO sequences is constant with the only exception that WTW may be smaller if $t_{j}$ $=0$.

A more flexible model that captures decreasing impatience not only for the present, but also for future time points, is generalized hyperbolic discounting (Loewenstein and Prelec, 1992). It is defined by 


$$
\varphi(t)=(1+h t)^{-r / h},
$$

with $\mathrm{h} \geq 0$ and $\mathrm{r}>0$. Here $\mathrm{h}$ can be interpreted as an index of decreasing impatience. Stationarity with constant discounting $\mathrm{e}^{-\mathrm{rt}}$ is the limiting case for $\mathrm{h} \rightarrow 0$ (Loewenstein and Prelec 1992). This family incorporates several popular hyperbolic families other than quasi-hyperbolic discounting. Mazur (1987) and Harvey (1995) considered proportional discounting $(\mathrm{h}=\mathrm{r})$, and Harvey (1986, Eq. 7) considered the special case $\mathrm{h}=1$.

Rohde (2007) proposed the hyperbolic factor for analyzing generalized hyperbolic discounting. For a TTO sequence $\mathrm{t}_{0}, \ldots, \mathrm{t}_{\mathrm{n}}$, the hyperbolic factor is defined as

$$
\text { hyperbolic factor }(\mathrm{i}, \mathrm{j})=\frac{\left(\mathrm{t}_{\mathrm{j}}-\mathrm{t}_{\mathrm{i}}\right)-\left(\mathrm{t}_{\mathrm{j}-1}-\mathrm{t}_{\mathrm{i}-1}\right)}{\mathrm{t}_{\mathrm{i}}\left(\mathrm{t}_{\mathrm{j}-1}-\mathrm{t}_{\mathrm{i}-1}\right)-\mathrm{t}_{\mathrm{i}-1}\left(\mathrm{t}_{\mathrm{j}}-\mathrm{t}_{\mathrm{i}}\right)}
$$

for all $\mathrm{j}>\mathrm{i}$. For one TTO sequence as in Eq. 3.1 with $\mathrm{n}=5,15(=5+4+3+2+1)$ hyperbolic factors can be calculated. The following result adapts Rohde's (2007) Theorems 3.3, 3.4, and 3.5 to TTO sequences.

OBSERVATION 7.2. For generalized hyperbolic discounting, $\varphi(t)=(1+h t)^{-\mathrm{r} / \mathrm{h}}$, the denominator in Eq. 7.3 is always positive, and the hyperbolic factor is always equal to h, independent of i, j, and the TTO sequence considered. For constant discounting (stationarity), the hyperbolic factor is always zero. For quasi-hyperbolic discounting the hyperbolic factor is nonnegative if $\mathrm{t}_{\mathrm{i}-1}=0$ and it is zero if $\mathrm{t}_{\mathrm{i}-1}>0$.

Thus, we can readily calculate the hyperbolic factor for TTO sequences and can then test many popular models of discounting.

Halevy (2007) introduced a model for risky intertemporal choice where time inconsistencies are generated by probability weighting. TTO curves then measure the curvature of Halevy's probability weighting, with linearity, convexity, and concavity of one corresponding with the other. Halevy's model can be combined with implicitrisk assumptions that can generate increasing impatience, a topic discussed in more detail in the following section. 


\section{Method of Experiment}

In the next sections we present and discuss an experiment using TTO sequences to analyze intertemporal choice.

Participants. N=55 subjects took part, 28 male and 27 female. There were 31 students from Erasmus University Rotterdam, 21 of whom from finance or economics and the others from various other disciplines. The remaining 24 students were from Maastricht University ( 1 economics, 1 finance, and the rest from various other disciplines).

Motivating subjects. Every subject received $€ 10$ for participation. All payoffs in the stimuli were hypothetical. This point is discussed in Section 11.

Procedure. The experiment was run by computer, and subjects were interviewed individually. On average, the task took 15 minutes per subject. We ran extensive pilots with 53 subjects in order to determine the appropriate setup.

We took one month as the unit of time. Subjects first went through a training phase, where preferences $(0: 700)<(1: 900)$ and $(0: 700)>(600: 900)$ were mostly observed. Then, in a training matching task, we asked for the value $t$ to generate the indifference $(0: 700) \sim(\mathrm{t}: 900)$, and then for the value $\mathrm{t}$ to generate the indifference $(0: 2800) \sim(\mathrm{t}: 3300)$.

Stimuli. We elicited four TTO sequences for each subject (Table 8.1). Every sequence consisted of 5 steps $(n=5)$. All tasks were matching tasks, similar to the last task of the training phase.

The computer screen is given in the Appendix. The pilots suggested that a direct successive elicitation of the time points $\mathrm{t}_{1}, \ldots, \mathrm{t}_{5}$ of one TTO sequence could generate order effects. Hence, in the main experiment we first elicited $t_{1}$ for every TTO sequence, next $t_{2}$ for every TTO sequence, and so on. 
TABLE 8.1. Parameters for the four TTO sequences

\begin{tabular}{llll}
\hline sequences & $\mathrm{t}_{0}$ & $\beta$ & $\gamma$ \\
\hline I & 0 months & $€ 700$ & $€ 900$ \\
II & 0 months & $€ 2800$ & $€ 3300$ \\
III & 5 months & $€ 700$ & $€ 900$ \\
IV & 0 months & $€ 1600$ & $€ 1900$ \\
\hline
\end{tabular}

The outcomes $\beta, \gamma$, and the initial time point $\mathrm{t}_{0}$ are as in Eq. 3.1.

Analysis. We did all tests both parametrically and non-parametrically. These always gave similar results, and we only report the non-parametric tests.

Analysis of Group Averages. Changes in WTW indicate whether subjects satisfy constant, decreasing or increasing impatience. We tested for constant WTW for each TTO sequence separately using a Friedman test.

Next, for every single pair of consecutive WTWs (for $d_{i}$ and $d_{i-1}$ ) we tested equality using Wilcoxon tests. We also tested equality of WTW between the first questions of sequence I $((0: 700) \sim(t: 900))$ and of sequence III $((5: 700) \sim(t: 900))$. Because these concern the same outcomes, stationarity predicts that WTW be the same. We checked whether the temporal attitude suggested by this comparison is consistent with the temporal attitude suggested by comparisons within sequence I. That is, we checked whether the change in WTW from the first question of sequence I to the first question of sequence III has the same sign as the first change in WTW within sequence I.

Analyses of Individual Data. A subject was classified as exhibiting increasing (constant, decreasing) impatience if at least $50 \%$ of her changes in WTW suggested so, where we considered all sequences together. A double classification as constant or increasing (50\% constant and 50\% increasing) was reclassified as increasing, with a similar procedure for decreasing. A double classification as increasing and decreasing was taken as unclassified, as were all other cases. We used these conservative criteria to reduce the effects of response error. Such a threshold of $50 \%$ has been used before 
in the literature (Abdellaoui 2000). We tested whether significantly more subjects are classified as increasingly or decreasingly impatient using Wilcoxon.

Next, we tested whether quasi-hyperbolic discounting holds. For every subject we split all changes in WTW of all TTO sequences into two groups: the group containing all changes in WTW where the first time point was 0 , and the group containing the rest. For both groups, we chose the same $50 \%$ classification as before. Under quasi-hyperbolic discounting, the WTW should increase in the former group and be constant in the latter. We performed similar Wilcoxon tests as before.

We developed global heuristic measures of convexity of the TTO curve. For example, the normalized area above the measured TTO curve is a plausible index of convexity and of decreasing impatience. This area is a monotonic transform of the decreasing-impatience index (DI-index), defined by

$$
\text { DI-index }=\sum_{j=1}^{n-1}\left(\frac{i}{n}-\tilde{t}_{i}\right) \text {, with } \tilde{t}_{i} \text { the normalization of } t_{i}\left(\tilde{t}_{i}=\frac{t_{i}-t_{n}}{t_{0}-t_{n}}\right) \text {. }
$$

The DI-index bears some resemblance with the Gini-index in inequality measurement.

For deviations from stationarity, absolute values of deviations from linearity are more relevant. Thus, we defined the non-stationarity index (NS-index) as

$$
\text { NS-index }=\sum_{\mathrm{i}=1}^{\mathrm{n}-1}\left|\frac{\mathrm{i}}{\mathrm{n}}-\tilde{\mathrm{t}}_{\mathrm{i}}\right| \text {. }
$$

It provides an overall index of deviation from stationarity and proneness to inconsistencies without concern for the direction of the deviation. To the extent that stationarity is rational, the NS-index could be interpreted as an irrationality index.

We calculated the DI and NS indexes for each subject. We also calculated the hyperbolic factors as explained in Section 7. We compared the indexes of all subjects between sequences by means of Wilcoxon signed rank tests. To test for a possible special effect of first questions, we also considered sequences with the first step left out. We computed the DI-index for these reduced sequences as follows: DI-index $=$ $\sum_{i=1}^{3}\left(\frac{i}{4}-\tilde{t}_{i+1}\right)$, with $\tilde{t}_{i}$ the normalization $\tilde{t}_{i}=\frac{t_{i}-t_{3}}{t_{0}-t_{3}}$. 


\section{Results from Eyeballing the TTO curves}

FIGURE 9.1. The TTO curves $\tau$ of several subjects

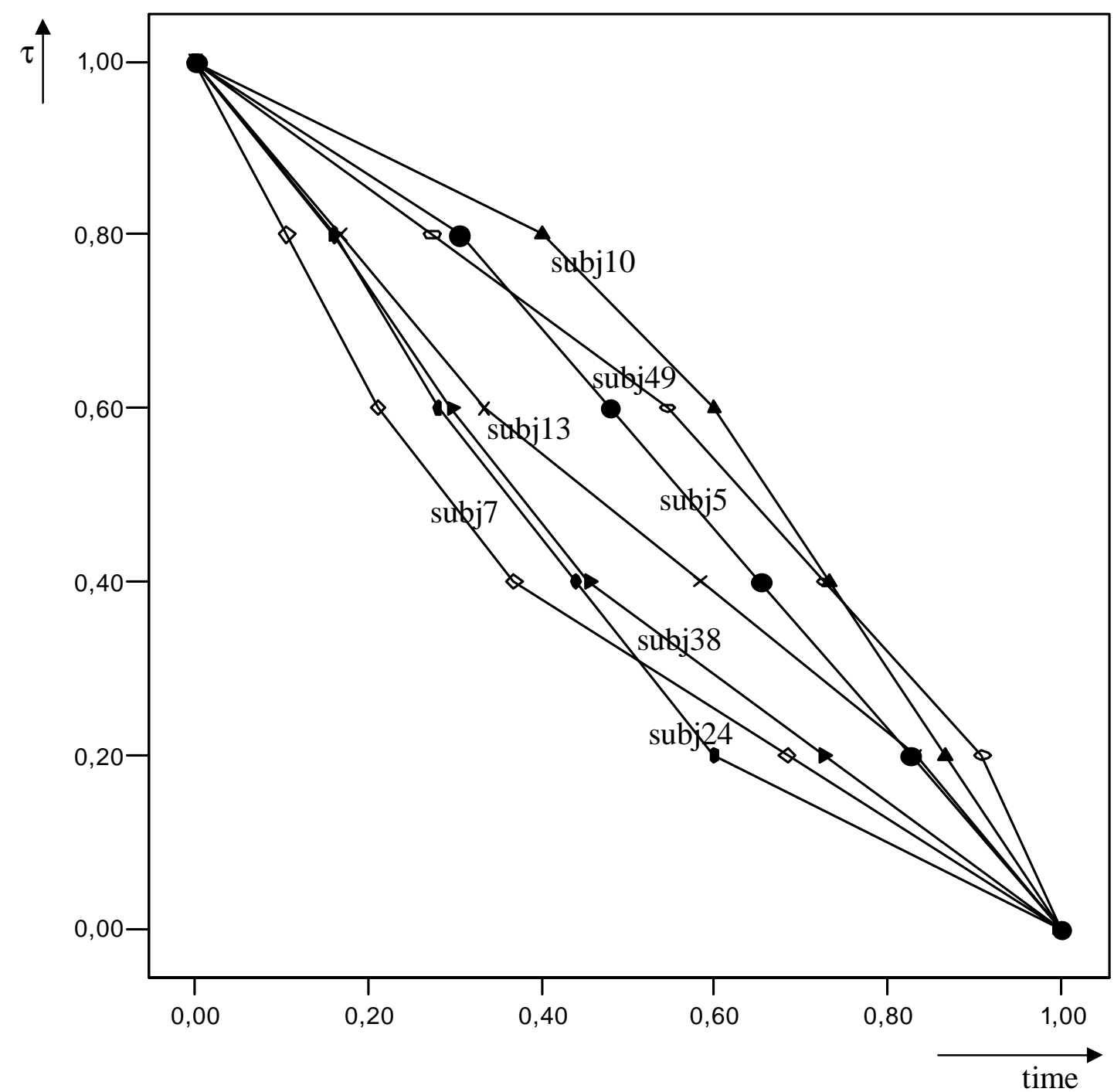

Before presenting detailed statistical results, we present heuristic results that can immediately be inferred from eyeballing TTO curves. Figure 9.1 displays seven TTO curves, obtained from seven subjects, on normalized time intervals. We immediately see that the curve of subject 7 is more convex, implying more decreasing impatience, than the curve of subject 38. By Theorem $6.3 \mathrm{i}$, subject 7 is more prone to time inconsistency and arbitrage than subject 38. Subject 24's curve is also always below that of subject 38, suggesting more decreasing impatience. Locally around 0.45 , subject 38 exhibits more convexity though, so that the ordering of convexity, while holding throughout most of the domain, does not hold universally. The curves of 
subjects 7 and 24 intersect and there is no uniform ordering regarding their degree of nonstationarity over the whole interval $\left[\mathrm{t}_{0}, \mathrm{t}_{5}\right]$.

There are several concave curves, exhibiting increasing rather than decreasing impatience. Theorem 6.3ii shows that subject 10 is more prone to time inconsistency than subject 5. The DI values are 0.63 (subject 7), 0.52 (subject 24), and 0.36 (subject 38). They suggest that, whereas there is no unambiguous ordering between subjects 7 and 24 as we saw before, subject 7 exhibits more decreasing impatience overall than subject 24. Similarly, subject 24 does so more than subject 38. Subjects 5, 10, and 49 exhibit increasing impatience. Accordingly, their DI-indexes will be negative, being -0.26 (subject 5), -0.60 (subject 10), and -0.45 (subject 49). Overall, subject 10 exhibits more increasing impatience than subject 49 and subject 49 exhibits more than subject 5 .

The DI-index of subject 13 is 0.08 , and this subject exhibits little decreasing or increasing impatience in an overall sense. Yet, this subject does deviate from stationarity. This is indicated by the NS index, which is 0.15 for this subject.

\section{Results and Statistical Tests}

\section{Group Averages}

Figure 10.1 gives the TTO curves constructed from the medians of the answers of all subjects. The curves suggest that subjects are increasingly impatient in the beginning and near future, and constantly impatient thereafter. Statistical analyses confirm this pattern. The Friedman tests rejected constantness of the WTW $(p<0.01)$ for all sequences. We repeated the test with the first WTW excluded. As expected, then the null hypothesis of constant WTW is not rejected ( $\mathrm{p}>0.20$ for all tests). Thus, our findings suggest that people satisfy stationarity for time points beyond a certain threshold. From the third sequence we can see that this threshold exceeds 5 months. 
Figure 10.2 shows median WTWs. The vertical axes all have the same scale and give the WTW. We can clearly see that the WTW drops in the beginning and remains more or less constant later on for every sequence. This is confirmed by Wilcoxon tests. The results of the Wilcoxon test are summarized in Table 10.1. The WTW changed significantly in the first steps $\left(d_{2}-d_{1}\right)(\alpha=0.01)$. The WTW decreases there, suggesting increasing impatience. The WTW increases in the second step $\left(\mathrm{d}_{3}-\right.$ $\mathrm{d}_{2}$ ) for sequence III $(\alpha=0.05)$. No other changes are significant at $\alpha=0.05$.

FIGURE 10.1. The TTO curves $\tau$ for median answers of the four TTO sequences
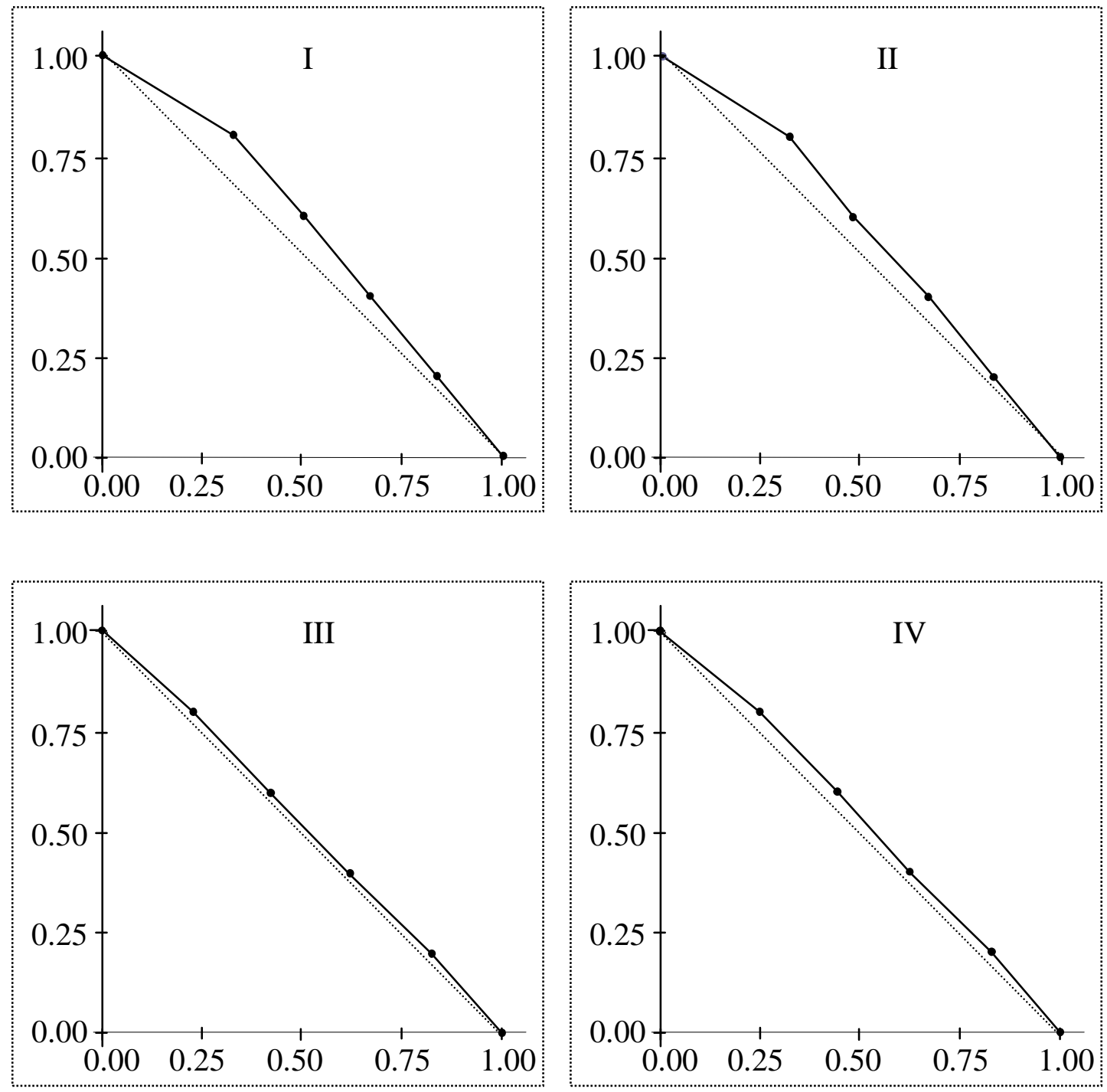


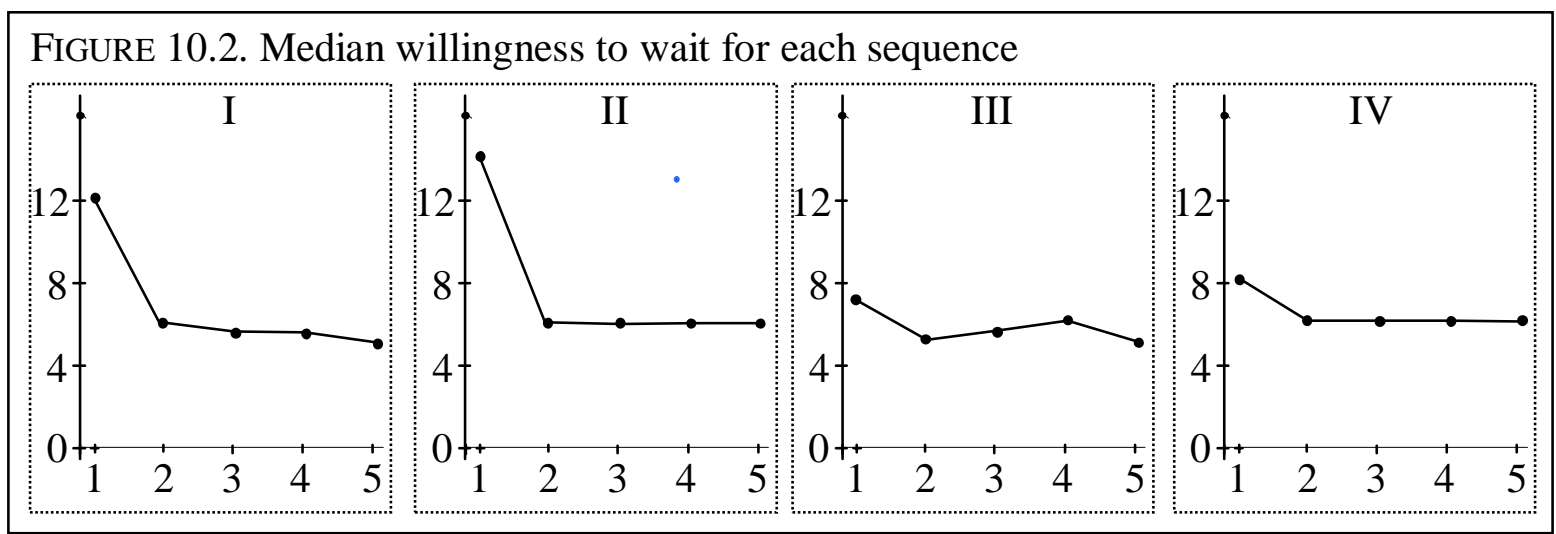

TABLE 10.1. Wilcoxon signed rank tests: Z (p-value, 2-tailed)

\begin{tabular}{lcccr}
\hline & \multicolumn{5}{c}{ WTW } \\
\cline { 2 - 5 } Sequence & $\mathrm{d}_{2}-\mathrm{d}_{1}$ & $\mathrm{~d}_{3}-\mathrm{d}_{2}$ & $\mathrm{~d}_{4}-\mathrm{d}_{3}$ & $\mathrm{~d}_{5}-\mathrm{d}_{4}$ \\
\hline I & $-4.40(0.000)$ & $-0.51(0.612)$ & $-0.63(0.531)$ & $-0.34(0.732)$ \\
II & $-4.50(0.000)$ & $1.35(0.176)$ & $-0.93(0.352)$ & $-0.98(0.329)$ \\
III & $-3.39(0.001)$ & $2.00(0.046)$ & $-0.29(0.769)$ & $-0.95(0.341)$ \\
IV & $-3.19(0.001)$ & $1.03(0.302)$ & $-0.41(0.681)$ & $1.05(0.293)$ \\
\hline
\end{tabular}

A Wilcoxon test shows that the first WTW of the third sequence is significantly lower $(\mathrm{p}<0.01)$ than the first WTW of the first sequence. Thus, subjects are consistent between sequences I and III.

\section{Individual Data}

The individual data confirm the preceding findings. Subjects are increasingly impatient for time points close to 0 and constantly impatient for later time points. The classification of subjects based on all sequences together yields 18 subjects exhibiting constant impatience, 3 exhibiting decreasing impatience, 10 exhibiting increasing impatience, and 24 not classified (Table 10.2). Thus, based on this classification we cannot say much about the behavior of individual subjects. The Wilcoxon test shows that there is more tendency towards increasing than towards decreasing impatience $(\mathrm{p}=0.052)$. In the group of all questions with a first time point zero, 8 subjects exhibit constant impatience, 3 subjects exhibit decreasing impatience, 36 subjects exhibit increasing impatience, and 8 subjects could not be classified. This suggests that most 
subjects indeed are increasingly impatient for time point zero, which is supported by the Wilcoxon test $(\mathrm{p}=0.000)$. In the other group (first time point positive), 21 subjects exhibit constant impatience, 5 subjects exhibit decreasing impatience, 6 subjects exhibit increasing impatience, and 23 subjects could not be classified. Thus, it appears that most subjects indeed exhibit constant impatience for time points not too close to 0 .

TABLE 10.2. Classification of individuals

\begin{tabular}{lcccc}
\hline & \multicolumn{4}{c}{ Impatience } \\
\cline { 2 - 5 } Questions & Constant & Decreasing & Increasing & unclassified \\
\hline all & 18 & 3 & 10 & 24 \\
time point 0 & 8 & 3 & 36 & 8 \\
time point $>0$ & 21 & 5 & 6 & 23 \\
\hline
\end{tabular}

Calculations of the hyperbolic factors revealed that positivity of the denominator in Eq. 7.3, a necessary condition for generalized hyperbolic discounting (Observation 7.2) was widely violated, for virtually all subjects in several questions. This provides evidence against generalized hyperbolic discounting, and the hyperbolic factor cannot be calculated in many situations.

We report the indexes of decreasing impatience (DI-index) and of nonstationarity (NS-index) to compare subjects. The medians of the DI-indexes (regarding decreasing impatience) are significantly negative for all 4 sequences ( $\mathrm{p}<$ 0.01) so that subjects are increasingly impatient overall. The medians of the DI-index were $-0.33,-0.28,-0.092$, and -0.19 , respectively. The third sequence had both a lower NS-index and a lower absolute value of the DI-index. This is probably caused by the fact that the third sequence starts closer to the threshold from whereon subjects satisfy constant impatience. The DI-indexes of the reduced sequences, the sequences without the first steps, did not deviate significantly from zero, indicating that the increasing impatience found earlier is indeed due to the first step of every sequence.

We proceed by considering only the DI-index and NS-index of the complete sequences. Based on a Wilcoxon signed rank test, the DI-index and the NS-index are significantly different for every sequence $(\mathrm{p}<0.01)$, where the NS-index is always 
larger than minus the DI-index. Because most indexes of decreasing impatience are negative, this finding implies that for most subjects the TTO curve $\tau$ intersects the curve belonging to a linear TTO curve at least once. Most subjects are, therefore, not clearly increasingly impatient or clearly decreasingly impatient, but are a mixture of both.

There was no significant difference in the DI-index and the NS-index between sequences I and II and between sequences III and IV. For all other pairs of sequences, the sequence with the higher sequence number provided significantly higher DIindexes and significantly lower NS-indexes than the ones before $(\mathrm{p}<0.01$ for all but one, $\mathrm{p}<0.05$ for all). Thus, subjects became less non-stationary and more decreasingly impatient or, equivalently, less increasingly impatient in later sequences.

On average, men had higher DI indexes and lower NS indexes, except for the DI index in sequence III, but the differences were usually not significant.

\section{Discussion of the Experiment}

Our subjects satisfy increasing impatience for small delays and constant impatience thereafter. Thus, we find a kind of reversed quasi-hyperbolic discounting, where impatience is constant after a certain threshold but is increasing rather than decreasing in the beginning. Impatience, however, continues to increase up to 5 months and is not constant immediately after the present. Informal discussions with subjects indicated that they understood the questions and knew what they wanted to answer. There was clear support for our finding of increasing impatience from these informal discussions. Many students indicated that they did not mind a delay much at first, but after a long wait they disliked further delays more. This finding is opposite to subjects becoming more insensitive to delays over time, as is commonly assumed in the literature.

Our finding of increasing impatience is consistent with several other studies (Carbone 2008; Gigliotti and Sopher, 2004; Read, Airoldi and Loewe, 2005; Read, Frederick, Orsel, and Rahman, 2005; Rubinstein, 2003; Sayman and Onculer, 2007). Read, Frederick, Orsel, and Rahman (2005) found that hyperbolic discounting is only 
observed when time is described in delay terms as opposed to calendar time terms. Rubinstein (2003) reported three experiments that provide evidence against constant or decreasing impatience. Bommier (2006) and Dasgupta and Maskin (2005) gave theoretical reasons why increasing impatience can occur. Other studies found neither increasing nor decreasing impatience, so that stationarity was not rejected (Sopher and Seth 2006; Holcomb and Nelson 1992).

The importance of using real incentives rather than hypothetical choice is well understood in the literature today. We nevertheless used hypothetical choice, with a flat fee for participation, for a number of reasons. First, for intertemporal choice, reliable future arrangements are hard to implement, not only for the experimenters but, more importantly, also for the subjects who will face considerable transaction costs. The latter will distort the experiment. There have been some impressive studies in the literature that succeeded in implementing real incentives in intertemporal choice, but they always concerned relatively small time periods. Here, discounting can be expected to be relatively weak, with a strong present bias. This holds the more so because real incentives have to involve relatively small payments that will not easily dominate the transaction costs.

Although several studies have found differences between real and hypothetical choice (Hertwig and Ortmann, 2001), the majority of studies have found that for cognitively simple tasks such as those in our experiments the behavioral patterns are the same (Camerer and Hogarth 1999). In the intertemporal choices in our experiment, there is no incentive for our subjects to please the experimenter one way or the other, unlike experiments about social behavior. Ways to implement real incentives for intertemporal choice with large time delays is an important topic for future research.

The measurement of TTO sequences is chained, which means that answers given in one question are an input in following questions. A drawback is that order effects can occur. It is, however, unlikely that such order effects would have caused the increasing impatience we found. The setup of the experiment made it hard for subjects to notice that the questions were chained and that several of them together served to elicit sequences. A second drawback of chaining question is that it leads to a propagation of errors, with an error in answer 1 affecting the error in future questions. Propagations of errors in similar chained measurements have been analyzed by Bleichrodt and Pinto (2000) and Abdellaoui et al. (2005). Both studies 
concluded that the effect of error propagation on chained measurement was small. Depending on the error theory assumed, smaller errors may result when measuring a distance $\left[\mathrm{t}_{0}, \mathrm{t}_{5}\right]$ through five intermediate steps rather than in one blow.

Many studies that provide evidence in favor of decreasing impatience elicit indifference values in the outcome dimension. They fix two time points and one outcome and elicit a second outcome that makes the subject indifferent between the two timed outcome streams. We elicit indifference values in the time dimension. Because we are interested in properties of the discount function, and not of the utility function, it is more natural to focus subjects' attention on this dimension. Because, by the construction of a TTO sequence, utilities cancel out from the equations, our method does not require richness in the outcome dimension and can, for instance, be used with qualitative health outcomes. It naturally exploits the richness in the time dimension that is available anyhow.

Although eliciting indifferences in the time dimension has not been very common, it has been used on a number of occasions, for instance by Mazur (1987). He conducted experiments with pigeons instead of humans. Green, Fristoe and Myerson (1994) did similar experiments with humans. These studies exploited the richness of the time dimension to study temporal preference similarly as we did. They, however, still assumed linear utility.

We chose matching to directly elicit indifferences rather than derive indifferences from choices. There have been many debates about the pros and cons of matching versus choice. A drawback of choice is that subjects more easily resort to noncompensatory heuristics than they do for matching (Brandstätter, Gigerenzer, and Hertwig 2006; Huber, Ariely, and Fischer 2001, p. 72; Montgomery 1983; Tversky 1972). A drawback of matching is that it generates biases of its own, with scale compatibility the most well known bias (Huber, Ariely, and Fischer 2001; Bostic, Herrnstein, and Luce 1990; Tversky, Sattath, and Slovic 1988). A feature of TTO sequences that supports the use of matching questions is that TTO sequences provide robustness against such distortions. For example, assume that a subject overweights the time dimension because of scale compatibility. We have

$$
\lambda\left(\ln \left(\varphi\left(\mathrm{t}_{\mathrm{j}-1}\right)\right)-\ln \left(\varphi\left(\mathrm{t}_{\mathrm{j}}\right)\right)\right)=\ln (\mathrm{U}(\gamma))-\ln (\mathrm{U}(\beta))
$$


with $\lambda>1$ instead of $\lambda=1$ as it was in Eq. 3.4 and its proof. Then still all our inferences and applications of the TTO sequence remain correct. They continue to be equally spaced in $\ln (\varphi)$ units, which is all we used in our analyses. Of course, biases different than those in Eq. 11.1 can exist. Still, TTO sequences provide robustness against at least those parts of the biases that have the same effect on all questions. The main reason for us to choose matching when eliciting the TTO sequences is that matching is considerably more tractable and efficient than choice. If its main bias is neutralized, then it becomes an especially attractive option, enhancing the tractability of the experiment.

Our findings suggest a number of new directions for intertemporal choice. Virtually all existing models, including quasi-hyperbolic discounting and generalized hyperbolic discounting, assume universal decreasing or constant impatience, and have no clear extension to allow for increasing impatience. However, even if group averages satisfy decreasing impatience, then there will still be individuals who exhibit increasing impatience, so that for any data fitting at the individual level such functions are required. For this reason we could not implement the planned test to discriminate which of the currently popular models fits the data better: they were all rejected. In particular Rohde's (2007) hyperbolic factor, targeted to the currently popular families, was not defined for a large portion of the answers given, which occurred at least once for virtually every subject. Hence, it is desirable that more general functions for discounting be developed.

\section{A Modification for the Health Domain}

We use the term time-tradeoff sequence in analogy to the time-tradeoff method commonly used in the health domain. There an indifference such as (living 10 years while being blind) (living 9 years in perfect health) is used to assess the relative utility of being blind, $\mathrm{U}($ blind $) / \mathrm{U}$ (perfect health), through the ratio $\varphi(9$ years $) / \varphi(10$ years), where $\varphi$ reflects a value of life duration which is often taken linear for convenience. These health questions are of the same format as the questions used in our time-tradeoff sequences. 
An interpretational difference between the time-tradeoff method from health and our method is that time reflects duration of experience in the health questions, whereas in our study time reflects waiting time before receipt of an outcome. To express the two different interpretations of time, we may use the term waiting-timetradeoff sequence, whereas the method in the health domain can then be called experience-time-tradeoff method. When no confusion will arise it is easier to use the short term without interpretation expressed, which is what we do in our paper. A topic for future study concerns the application of TTO sequences in the health domain.

\section{Conclusion}

TTO sequences are easy to administer and provide a general tool for analyzing intertemporal choice. They facilitate measurements of the discount function, qualitative and quantitative tests of impatience, quantifications of the degree of time inconsistency, and axiomatizations of parametric families of discounting.

\section{Appendix}

PROOF OF THEOREM 6.3. Because $\tau$ and $\tau^{*}$ are strictly decreasing functions, $\tau^{*}(\mathrm{t})=$ $\mathrm{f}(\tau(\mathrm{t}))$ for a strictly increasing function $\mathrm{f}$. Take any intervals $[\mathrm{d}, \mathrm{c}]$ and $[\mathrm{b}, \mathrm{a}]$ to the right of $[\mathrm{d}, \mathrm{c}](\mathrm{b}>\mathrm{d}$ and $\mathrm{a}>\mathrm{c})$ in the domain of $\mathrm{f}$. Then $\mathrm{a}=\tau(\mathrm{s}), \mathrm{b}=\tau(\mathrm{t}), \mathrm{c}=\tau(\mathrm{s}+\sigma)$, and $\mathrm{d}=\tau(\mathrm{t}+\sigma+\varepsilon)$ for some $\mathrm{s}<\mathrm{t}, \mathrm{s}+\sigma<\mathrm{t}+\sigma+\varepsilon, \sigma>0, \sigma+\varepsilon>0$. Because the ranges of $\mathrm{U}$ and $\mathrm{U}^{*}$ contain nondegenerate intervals with 0 as lower bound, there exist outcomes $\beta<\gamma$ with

$$
(\mathrm{s}: \beta) \sim(\mathrm{t}: \gamma)
$$

and outcomes $\beta^{*}<\gamma^{*}$ with

$$
\left(\mathrm{s}: \beta^{*}\right) \sim^{*}\left(\mathrm{t}: \gamma^{*}\right)
$$


(Here is where we crucially use continuity of utility.) Only the utility ratios $U(\beta) / U(\gamma)$ and $U^{*}\left(\beta^{*}\right) / U^{*}\left(\gamma^{*}\right)$ matter for all that follows and, hence, the particular choices of $\beta$, $\gamma, \beta^{*}, \gamma^{*}$ are immaterial for all that follows.

We have equivalence of the following statements:

$\mathrm{a}-\mathrm{b}=\mathrm{c}-\mathrm{d}$

$\tau(\mathrm{s})-\tau(\mathrm{t})=\tau(\mathrm{s}+\sigma)-\tau(\mathrm{t}+\sigma+\varepsilon)$

$\ln \varphi(\mathrm{s})-\ln \varphi(\mathrm{t})=\ln \varphi(\mathrm{s}+\sigma)-\ln \varphi(\mathrm{t}+\sigma+\varepsilon) ;$

$\varphi(\mathrm{s}) / \varphi(\mathrm{t})=\varphi(\mathrm{s}+\sigma) / \varphi(\mathrm{t}+\sigma+\varepsilon)$;

$(\mathrm{s}+\sigma: \beta) \sim(\mathrm{t}+\sigma+\varepsilon: \gamma)$.

We also have logical equivalence of the following statements:

$f(a)-f(b) \geq f(c)-f(d)$.

$\tau^{*}(\mathrm{~s})-\tau^{*}(\mathrm{t}) \geq \tau^{*}(\mathrm{~s}+\sigma)-\tau^{*}(\mathrm{t}+\sigma+\varepsilon)$

$\ln \varphi^{*}(\mathrm{~s})-\ln \varphi^{*}(\mathrm{t}) \geq \ln \varphi^{*}(\mathrm{~s}+\sigma)-\ln \varphi^{*}(\mathrm{t}+\sigma+\varepsilon)$

$\varphi^{*}(\mathrm{~s}) / \varphi^{*}(\mathrm{t}) \geq \varphi^{*}(\mathrm{~s}+\sigma) / \varphi^{*}(\mathrm{t}+\sigma+\varepsilon)$

$\left(\mathrm{s}+\sigma: \beta^{*}\right) \preccurlyeq\left(\mathrm{t}+\sigma+\varepsilon: \gamma^{*}\right)$

It is well-known that $\mathrm{f}$ is convex if and only if for all $\mathrm{a}, \mathrm{b}, \mathrm{c}, \mathrm{d}$ as above we have $\mathrm{f}(\mathrm{a})$ $f(b) \geq f(c)-f(d)$. As we have just demonstrated, this is, in view of Eq. A.1 and Eq. A. 2 and the independence of the choices $\beta, \gamma, \beta^{*}, \gamma^{*}$, the same as the requirement that $(\mathrm{s}+\sigma: \beta) \sim(\mathrm{t}+\sigma+\varepsilon: \gamma)$ imply $\left(\mathrm{s}+\sigma: \beta^{*}\right) \preccurlyeq\left(\mathrm{t}+\sigma+\varepsilon: \gamma^{*}\right)$ for all $\mathrm{s}, \mathrm{t}, \sigma, \varepsilon$ as above. That is, convexity of $\mathrm{f}$ is equivalent to more decreasing impatience for $\geqslant *$ than for $\geqslant$.

Reversing inequalities and weak preferences shows that concavity of $\mathrm{f}$ is equivalent to more increasing impatience for $\geqslant *$ than for $\geqslant$. 
FIGURE A.1. Layout of the computer screen

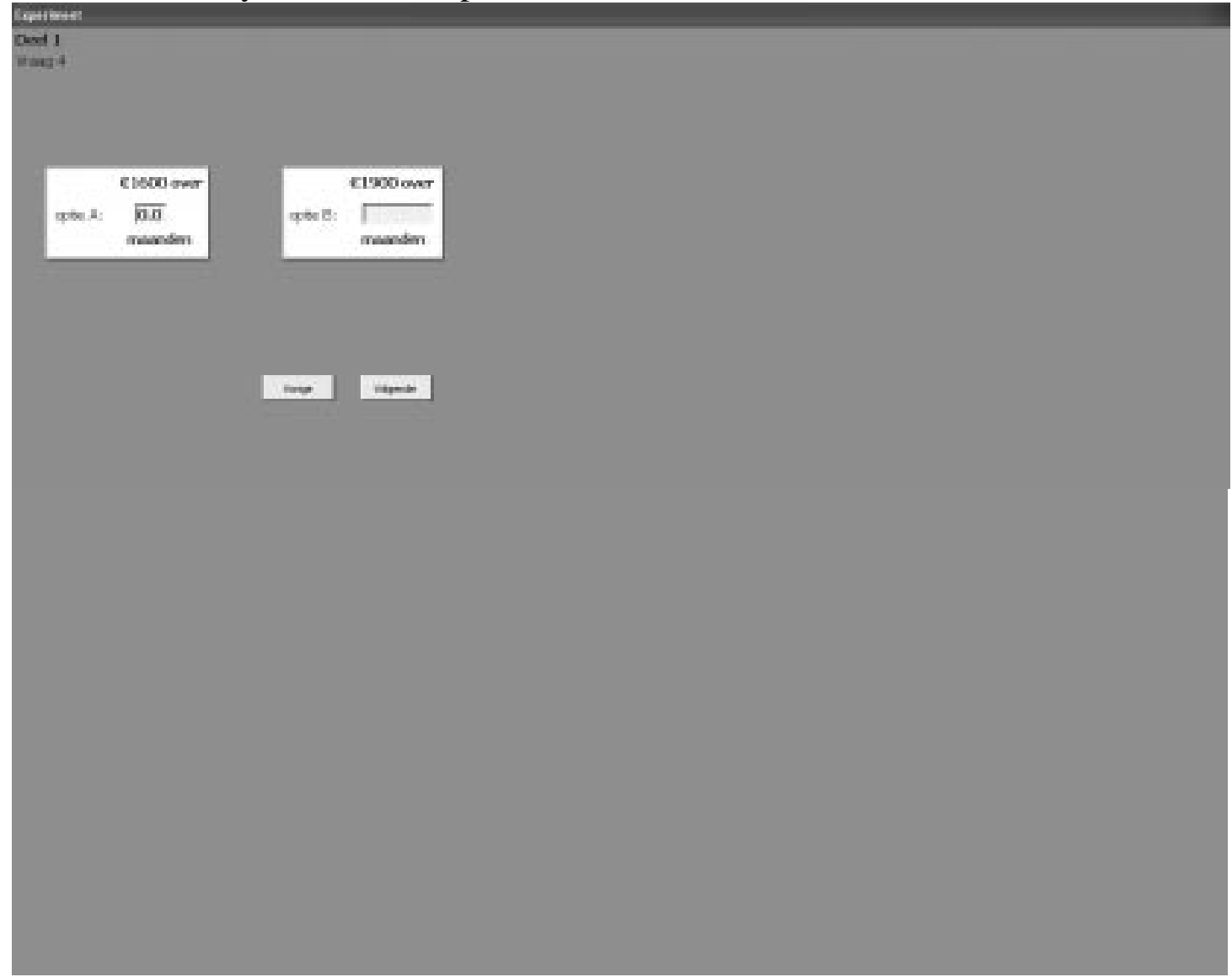

\section{References}

Abdellaoui, Mohammed (2000), "Parameter-Free Elicitation of Utilities and Probability Weighting Functions," Management Science 46, 1497-1512.

Abdellaoui, Mohammed, Frank Vossmann, \& Martin Weber (2005), "Choice-Based Elicitation and Decomposition of Decision Weights for Gains and Losses under Uncertainty," Management Science 51, 1384-1399.

Abdellaoui, Mohammed, Arthur E. Attema, \& Han Bleichrodt (2008), "Intertemporal Tradeoffs for Gains and Losses: An Experimental Measurement of Discounted Utility," iMTA/iBMG, Erasmus University, Rotterdam, the Netherlands. Akerlof, George A. (1991), "Procrastination and Obedience," American Economic Review, Papers and Proceedings 81, 1-19. 
Akerlof, George A. (2002), "Behavioral Macroeconomics and Macroeconomic Behavior," American Economic Review 92, 411-433.

Andersen, Steffen, Glenn W. Harrison, Morten I. Lau, \& E. Elisabet Rutstrom (2008),

“Eliciting Risk and Time Preferences," Econometrica 76, 583-618.

Angeletos, George-Marios, David Laibson, Andrea Repetto, Jeremy Tobacman, \& Stephen Weinberg (2001), “The Hyperbolic Consumption Model: Calibration, Simulation, and Empirical Evaluation," Journal of Economic Perspectives 15, $47-68$.

Asheim, Geir B. (1997), "Individual and Collective Time-Consistency," Review of Economic Studies 64, 427-443.

Barro, Robert J. (1999), "Ramsey Meets Laibson in the Neoclassical Growth Model," Quarterly Journal of Economics 114, 1125-1152.

Becker, Gary S. (1996), “Accounting for Tastes.” Harvard University Press, Cambridge, MA.

Bénabou, Roland \& Jean Tirole (2002), "Self-Confidence and Personal Motivation," Quarterly Journal of Economics 117, 871-915.

Bleichrodt, Han \& José Luis Pinto (2000), "A Parameter-Free Elicitation of the Probability Weighting Function in Medical Decision Analysis," Management Science 46, 1485-1496.

Bommier, Antoine (2006), "Uncertain Lifetime and Intertemporal Choice: Risk Aversion as a Rationale for Time Discounting," International Economic Review 47, 1223-1246.

Bostic, Raphael, Richard J. Herrnstein, \& R. Duncan Luce (1990), “The Effect on the Preference-Reversal Phenomenon of Using Choice Indifferences," Journal of Economic Behavior and Organization 13, 193-212.

Brandstätter, Eduard, Gerd Gigerenzer, \& Ralph Hertwig (2006), “The priority heuristic: Making choices without trade-offs," Psychological Review 113, 409-432.

Broome, John R. (1993), “Qalys,” Journal of Public Economics 50, 149-167.

Camerer, Colin F. \& Robin M. Hogarth (1999), "The Effects of Financial Incentives in Experiments: A Review and Capital-Labor-Production Framework," Journal of Risk and Uncertainty 19, 7-42. 
Carbone, Enrica (2008), "Temptations and Dynamic Consistency," Theory and Decision 64, 229-248.

Chapman, Gretchen B. (1996), "Temporal Discounting and Utility for Health and Money," Journal of Experimental Psychology: Learning, Memory, and Cognition 22, 771-791.

Constantinides, George M. (1990), "Habit Formation: A Resolution of the Equity Premium Puzzle," Journal of Political Economy 98, 519-543.

Cubitt, Robin P. \& Robert Sugden (2001), “On Money Pumps,” Games and Economic Behavior 37, 121-160.

Dasgupta, Partha \& Eric Maskin (2005), “Uncertainty and Hyperbolic Discounting," American Economic Review 95, 1290-1299.

DellaVigna, Stefano \& Ulrike Malmendier (2004), "Contract Design and SelfControl: Theory and Evidence," Quarterly Journal of Economics 119, 353-402. Dolan, Paul (2000), “The Measurement of Health-Related Quality of Life for Use in Resource Allocation Decisions in Health Care.” In Antony J. Culyer \& Joseph P. Newhouse (eds.), Handbook of Health Economics, Elsevier, Amsterdam, $1723-1760$.

Frederick, Shane (1999), "Discounting, Time Preference, and Identity,” Ph.D. Thesis, Department of Social and Decision Sciences, Carnegie Mellon University. Frederick, Shane, George F. Loewenstein, \& Ted O’Donoghue (2002), “Time Discounting and Time Preference: A Critical Review," Journal of Economic Literature 40, 351-401.

Gigliotti, Gary \& Barry Sopher (2004), “Analysis of Intertemporal Choice: A New Framework and Experimental Results," Theory and Decision 55, 209-233. Gilboa, Itzhak (1989), "Expectation and Variation in Multi-Period Decisions," Econometrica 57, 1153-1169.

Gold, Marthe R., Joanna E. Siegel, Louise B. Russell, \& Milton C. Weinstein (1996), “Cost-Effectiveness in Health and Medicine.” Oxford University Press, New York.

Green, Leonard, Nathanael Fristoe, \& Joel Myerson (1994), “Temporal Discounting and Preference Reversals in Choice between Delayed Outcomes," Psychonomic Bulletin and Review 1, 383-389. 
Gruber, Jonathan \& Botond Köszegi (2001), "Is Addiction "Rational”? Theory and Evidence," Quarterly Journal of Economics 116, 1261-1303.

Gul, Faruk \& Wolfgang Pesendorfer (2005), "The Revealed Preference Theory of

Changing Tastes," Review of Economic Studies 72, 429-448.

Guyse, Jeffery L., L. Robin Keller, \& Thomas Eppel (2002), "Valuing Environmental

Outcomes: Preferences For Constant or Improving Sequences,” Organizational Behavior and Human Decision Processes 87, 253-277.

Halevy, Yoram (2007), "Strotz Meets Allais: Diminishing Impatience and the Certainty Effect," American Economic Review, forthcoming.

Harris, Christopher \& David Laibson (2001), "Dynamic Choices of Hyperbolic Consumers," Econometrica 69, 935-957.

Harvey, Charles M. (1986), "Value Functions for Infinite-Period Planning," Management Science 32, 1123-1139.

Harvey, Charles M. (1995), "Proportional Discounting of Future Costs and Benefits," Mathematics of Operations Research 20, 381-399.

Hertwig, Ralf \& Andreas Ortmann (2001), "Experimental Practices in Economics: A Challenge for Psychologists?," Behavioral and Brain Sciences 24, 383-403.

Holcomb, James H., \& Paul S. Nelson (1992), “Another Experimental Look at Individual Time Preference," Rationality and Society 4, 199-220.

Huber, Joel, Dan Ariely, \& Gregory Fischer (2001), "Expressing Preference in a Principal-Agent Task: A Comparison of Choice, Rating, and Matching,” Organizational Behavior and Human Decision Processes 87, 66-90.

Keller, L. Robin \& Elisabetta Strazzera (2002), "Examining Predictive Accuracy among Discounting Models," Journal of Risk and Uncertainty 24, 143-160.

Koopmans, Tjalling C. (1960), "Stationary Ordinal Utility and Impatience," Econometrica 28, 287-309.

Krabbe, Paul F.M. \& Gouke J. Bonsel (1998), "Sequence Effects, Health Profiles, and the QALY Model: In Search of Realistic Modeling," Medical Decision Making $18,178-186$.

Krusell, Per P. \& Anthony A. Smith (2003), "Consumption-Savings Decisions with Quasi-Geometric Discounting, Econometrica 71, 365-375.

Kydland, Finn E. \& Edward C. Prescott (1977), "Rules rather than Discretion: The Inconsistency of Optimal Plans," Journal of Political Economy 85, 473-491. 
Laibson, David I. (1997), “Golden Eggs and Hyperbolic Discounting,” Quarterly Journal of Economics 112, 443-477.

Laibson, David I. (1998), "Life-Cycle Consumption and Hyperbolic Discount Functions," European Economic Review 42, 861-871.

Loewenstein, George F. \& John Elster (1992), “Choice over Time.” Russell Sage Foundation, New York.

Loewenstein, George, and Drazen Prelec (1992), “Anomalies in intertemporal choice: evidence and an interpretation," Quarterly Journal of Economics, 107, 573-597.

Loewenstein, George F. \& Nachum Sicherman (1991), "Do Workers Prefer Increasing Wage Profiles?," Journal of Labor Economics 9, 67-84.

Loomes, Graham \& Linda McKenzie (1989), "The Use of QALYs in Health Care Decision Making," Social Science and Medicine 28, 299-308.

Luttmer, Erzo G. J., \& Thomas Mariotti (2003), “Subjective Discounting in an Exchange Economy,” Journal of Political Economy 111, 1-30.

Mazur, James E. (1987), “An Adjusting Procedure for Studying Delayed Reinforcement." In Michael L. Commons, James E. Mazur, John A. Nevin, \& Howard Rachlin (eds.), Quantitative Analyses of Behavior 5, 55-73, Lawrence Erlbaum, Hillsdale NJ.

Montgomery, Henry (1983), "Decision Rules and the Search for a Dominance Structure: Towards a Process Model of Decision Making." In Patrick C. Humphreys, Ola Svenson, \& Anna Vari (eds.), Analyzing and Aiding Decision Processes, North-Holland, Amsterdam.

Narens, Louis (2002), “Theories of Meaningfulness.” Lawrence Erlbaum, Mahwah, NJ.

O'Donoghue, Ted, \& Matthew Rabin (1999a), “Doing It now or later,” American Economic Review 89, 103-124.

O'Donoghue,Ted, \& Matthew Rabin (1999b), "Incentives for Procrastinators," Quarterly Journal of Economics 114, 769-816.

Peleg, Bezalel \& Menahem E. Yaari (1973), “On the Existence of a Consistent Course of Action when Tastes are Changing," Review of Economic Studies 40, 391-401. Phelps, Edmund S. \& Robert A. Pollak (1968), “On Second-Best National Saving and Game-Equilibrium Growth," Review of Economic Studies 35, 185-199. 
Prelec, Drazen (2004), "Decreasing Impatience: A Criterion for Non-Stationary Time Preference and "Hyperbolic" Discounting," Scandinavian Journal of Economics $106,511-532$.

Prelec, Drazen \& George F. Loewenstein (1991), "Decision Making over Time and under Uncertainty: A Common Approach,” Management Science 37, 770-786.

Read, Daniel, Mara Airoldi, \& German Loewe (2005), `Intertemporal Tradeoffs Priced in Interest Rates and Amounts: A Study of Method Variance," Working Paper.?

Read, Daniel \& Shane Frederick, Burco Orsel, \& Juwaria Rahman (2005), "Four Score and Seven Years from now: The Date/Delay Effect in Temporal Discounting," Management Science 51, 1326-1335.

Rohde, Kirsten I.M. (2007), “The Hyperbolic Factor: a Measure of Decreasing Impatience," Working Paper.

Rubinstein, Ariel (2003), "Economics and Psychology?" The Case of Hyperbolic Discounting"," International Economic Review 44, 1207-1216.

Samuelson, Paul A. (1937), “A Note on Measurement of Utility,” Review of Economic Studies 4 (Issue 2, February 1937), 155-161.

Sayman, Serdar \& Onculer, Ayse (2007), “An Investigation of Time-Inconsistency,” working paper.

Sopher, Barry \& Arnav Sheth (2006), "A Deeper Look at Hyperbolic Discounting," Theory and Decision 60, 219-255.

Stevens, Stanley S. (1946), "On the Theory of Scales of Measurement," Science 103 No 2648, 677-680.

Strotz, Robert H. (1956), "Myopia and Inconsistency in Dynamic Utility Maximization," Review of Economic Studies 23 (Issue 3, June 1956), 165-180. Thaler, Richard H. (1981), "Some Empirical Evidence of Dynamic Inconsistency," Economics Letters 8, 201-207.

Thaler, Richard H. \& Shlomo Benartzi (2004), "Save More tomorrow: Using Behavioral Economics to Increase Employee Saving," The Journal of Political Economy 112, S164-187.

Tversky, Amos (1972), "Elimination by Aspects: A Theory of Choice," Psychological Review 79, 281-299. 
Tversky, Amos, Shmuel Sattath, \& Paul Slovic (1988), "Contingent Weighting in Judgment and Choice," Psychological Review 95, 371-384.

van der Pol, Marjon \& John Cairns (2002), “A comparison of the Discounted Utility Model and Hyperbolic Discounting Models in the Case of Social and Private Intertemporal Preferences for Health," Journal of Economic Behavior and Organization 49, 79-96.

Wathieu, Luc (1997), "Habits and the Anomalies in Intertemporal Choice," Management Science 43, 1552-1563. 